\title{
Antidiabetic Components Contained in Vegetables and Legumes
}

\author{
Guang-Yan Tang, Xue-Juan Li and Hong-Yu Zhang *
}

School of Life Sciences, Shandong University of Technology, Zibo 255049, P. R. China

* Author to whom correspondence should be addressed; E-mail: zhanghy@sdut.edu.cn

Received: 9 May 2008; in revised form: 22 May 2008 / Accepted: 22 May 2008 / Published: 23 May 2008

\begin{abstract}
Epidemiological analyses in a large Chinese population have revealed that consumption of vegetables and legumes is inversely associated with the risk of type 2 diabetes (T2D). However, the health benefits of these plants have not been fully explained, which stimulated our interest to identify antidiabetic components from vegetables and legumes through searching medicinal databases, especially those containing traditional Chinese medicines. The results not only provide meaningful clues to understanding the antidiabetic potentials of these plants but also display the possibility of pinpointing food component functions by searching medicinal databases.
\end{abstract}

Keywords: Type 2 diabetes, vegetables, legumes, antidiabetic components, medicinal database

\section{Introduction}

It is well known that certain foods may have the potential to prevent diseases [1,2]. For instance, the Mediterranean diet is helpful to lowering the risks of coronary heart disease, cancer and cognitive impairment [3-5]. Consumption of green tea is beneficial for preventing cancer and Alzheimer's disease (AD) [6-8]. Recently, Villegas and co-workers reported that adherence to vegetables (including cruciferous vegetables, green leafy vegetables, yellow vegetables, allium vegetables, tomatoes and others) and legumes (including soybean, peanut, etc.) is inversely associated with the risk of type 2 diabetes (T2D) in a large Chinese population $[9,10]$. However, the health benefits of 
these plants have not been fully explained, which stimulated our interest to address this issue further. Considering the fact that some foods have been recognized as natural medicines, in particular some vegetables and legumes have been used as traditional medicines in China for many years, we speculated that it is highly possible to pinpoint food component functions by searching medicinal databases, especially those containing traditional Chinese medicines.

Figure 1. TCMD-documented vegetable and legume components with aldose reductase inhibitory or hypoplycemic activity.

$\mathrm{HO}$

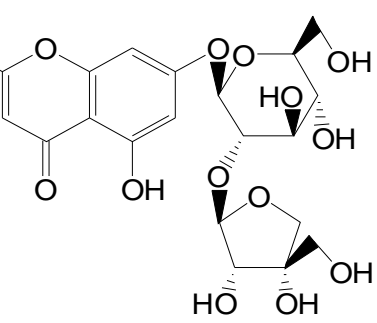

Apiin (Aldose reductase inhibitory, from Wildcelery)

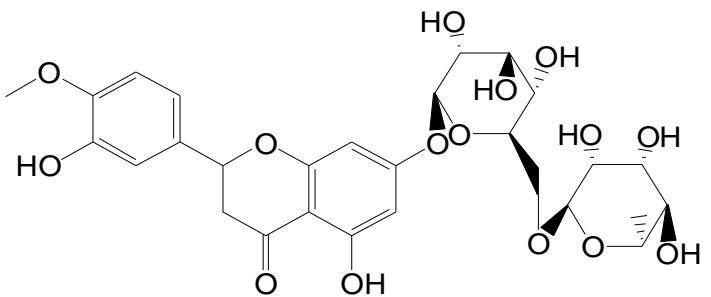

Hesperidin (Aldose reductase inhibitory, from Shepherd'sPurse)
$\mathrm{HO}$

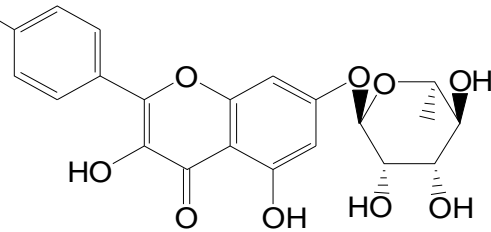

Kaempferol-7-rhamnoside (Aldose reductase inhibitory, from White kidney bean)

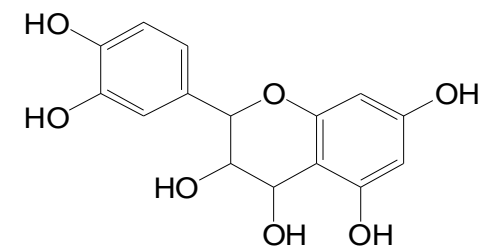

Leucocyanidin (Aldose reductase inhibitory, from Groundnut)

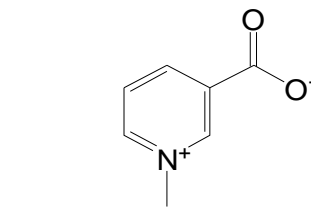

Trigonelline (Hypoplycemic, from Tomato, Eggplant, Cushaw and Pea)

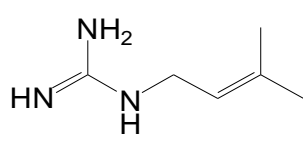

Galegine (Hypoplycemic, from Goat's-rue)

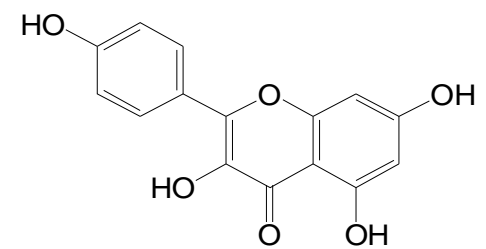

Kaempferol (Aldose reductase inhibitory, from Wild pea)

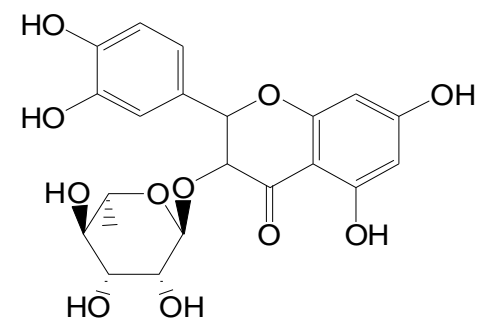

Quercitrin (Aldose reductase inhibitory, from Colewort)

\section{Results and Discussion}

Primarily, we searched the Traditional Chinese Medicine Database (TCMD), which documents $\sim 10,000$ components extracted from $\sim 4,600$ traditional medicinal agents [11]. Hundreds of components were identified from vegetables and legumes that are recorded in the TCMD. According to the pharmacological activity annotations, we found that some components (Figure 1) are directly 
associated with prevention and/or treatment of $\mathrm{T} 2 \mathrm{D}$, because of their aldose reductase inhibitory or hypoplycemic activity.

Besides, the functions of many other vegetable and legume components (e.g., antiatherosclerotic, antihypertensive, antilipemic, antithrombotic, lipase inhibitory, lipid peroxidation inhibitory, lipoxygenase inhibitory and platelet aggregation inhibitory) are also associated with ameliorating T2D (Table 1) [12-16].

Table 1. TCMD-documented vegetable and legume functional components associated with ameliorating type 2 diabetes.

\begin{tabular}{|c|c|c|}
\hline Compound & Activity & Source \\
\hline Aframodial & Antilipemic & Zingiber (Zingiber officinale Rosc.) \\
\hline Agavasaponin $\mathrm{C}$ & Platelet aggregation inhibitory & Garlic (Allium sativum L.) \\
\hline Allicin & Antihypertensive; & Shallot (Allium fislulosum L.); \\
\hline & Antithrombotic & Garlic (Allium sativum L.) \\
\hline Alliin & Antithrombotic; & Onion (Allium сера L.); \\
\hline & Platelet aggregation inhibitory & Garlic (Allium sativum L.) \\
\hline Bergapten & Antihypertensive & Tomato (Lycopersicon esculentum Miller) \\
\hline beta-Sitosterol & Antilipemic & Black soybean (Glycine max (L.) Merr.) \\
\hline Camphene & Antilipemic & $\begin{array}{l}\text { Zingiber (Zingiber officinale Rosc.); } \\
\text { Mint (Mentha haplocalyx Briq.) }\end{array}$ \\
\hline Daidzein & Lipase inhibitory & Black soybean (Glycine max (L.) Merr.) \\
\hline Ferulic acid & Platelet aggregation inhibitory & Onion (Allium сера L.) \\
\hline Genistein & Lipase inhibitory & Black soybean (Glycine max (L.) Merr.) \\
\hline Glycitein & Lipoxygenase inhibitory & Black soybean (Glycine max (L.) Merr.) \\
\hline Isoeruboside B & Platelet aggregation inhibitory & Garlic (Allium sativum L.) \\
\hline Isorhamnetin & $\begin{array}{l}\text { Antilipemic; } \\
\text { Platelet aggregation inhibitory }\end{array}$ & Cress (Oenanthe javanica (B1.)DC.) \\
\hline Kaempferol & $\Delta$-5-lipoxygenase inhibitory & Wild pea (Vicia amoena Fisch. ex DC.) \\
\hline Leucocyanidin & Platelet aggregation inhibitory & Groundnut (Arachis hypogaea L.) \\
\hline Lycopene & Antiatherosclerotic & $\begin{array}{l}\text { Tomato (Lycopersicon esculentum Miller); } \\
\text { Bitter gourd (Momordica charantia L.) }\end{array}$ \\
\hline Methyl allyl trisulfide & Platelet aggregation inhibitory & Garlic (Allium sativum L.) \\
\hline Myristicin & Platelet aggregation inhibitory & Wild celery (Apium graveolens L.) \\
\hline p-Coumaric acid & Antilipemic & Potato (Solanum tuberosum L.) \\
\hline Proto-iso-eruboside B & Antithrombotic & Garlic (Allium sativum L.) \\
\hline Rosmarinic acid & $\begin{array}{l}\text { Antithrombotic; } \\
\text { Platelet aggregation inhibitory }\end{array}$ & Mint (Mentha haplocalyx Briq.) \\
\hline 6-Shogaol & $\begin{array}{l}\text { Antihypertensive; } \\
\text { Platelet aggregation inhibitory }\end{array}$ & Zingiber (Zingiber officinale Rosc.) \\
\hline Solasonine & Platelet aggregation inhibitory & $\begin{array}{l}\text { Capsicum (Capsicum annuum L.); } \\
\text { Eggplant (Solanum melongena L.) }\end{array}$ \\
\hline Soyasaponin A1 & $\begin{array}{l}\text { Antilipemic; } \\
\text { Antithrombotic }\end{array}$ & Black soybean (Glycine max (L.) Merr.) \\
\hline Soyasaponin A2 & Antilipemic & Black soybean (Glycine max (L.) Merr.) \\
\hline Soyasaponin A3 & Lipoxygenase inhibitory & Black soybean (Glycine max (L.) Merr.) \\
\hline
\end{tabular}


Table 1. Cont.

\begin{tabular}{|c|c|c|}
\hline Soyasaponin A4 & Lipoxygenase inhibitory & Black soybean (Glycine max (L.) Merr.) \\
\hline Soyasaponin A5 & Lipoxygenase inhibitory & Black soybean (Glycine max (L.) Merr.) \\
\hline Soyasaponin A6 & Lipoxygenase inhibitory & Black soybean (Glycine max (L.) Merr.) \\
\hline Soyasaponin V & Lipoxygenase inhibitory & $\begin{array}{l}\text { Black soybean (Glycine max (L.) Merr.); } \\
\text { White kidney bean (Phaseolus vulgaris L.) }\end{array}$ \\
\hline Stigmasterol & Antilipemic & $\begin{array}{l}\text { Black soybean (Glycine max (L.) Merr.); } \\
\text { Purple haricot (Lablab purpureus (L.)Sweet); } \\
\text { Groundnut (Arachis hypogaea L.); } \\
\text { White kidney bean (Phaseolus vulgaris L.) }\end{array}$ \\
\hline Tomatine & Antihypertensive & Tomato (Lycopersicon esculentum Miller) \\
\hline 2-Vinyl-4H-1,3-dithiin & $\begin{array}{l}\text { Platelet aggregation inhibitory; } \\
\text { Antithrombotic; } \\
\text { 5-lipoxygenase inhibitory }\end{array}$ & Garlic (Allium sativum L.) \\
\hline
\end{tabular}

Furthermore, through comparing the structures of these components with those recorded in the Comprehensive Medicinal Chemistry (CMC) database (which records $\sim 8,000$ clinically used drugs) [17] and the MDL Drug Data Report (MDDR) database (which collects 145,000 drug candidates) [18], we found that some of these agents have been recognized by modern Western medicine (Table 2). Although some activities annotated in CMC and MDDR are not the same as displayed in TCMD, they are also associated with combating T2D. Taken together, the present analysis clearly indicates that vegetables and legumes indeed contain many antidiabetic components, which provide new clues to understanding the beneficial effects of vegetable and legume consumption on the risk of T2D $[9,10]$.

Table 2. CMC- and MDDR-documented vegetable and legume functional components associated with ameliorating type 2 diabetes.

\begin{tabular}{|l|l|}
\hline Compound & Activity \\
\hline \multirow{3}{*}{ Allicin } & Hypolipidemic (CMC/MDDR); \\
& Hypocholesterolemic (CMC); \\
& Platelet aggregation inhibitory (MDDR) \\
6-Shogaol & Cyclooxygenase inhibitory (MDDR); \\
beta-Sitosterinum (beta-Sitosterol) & Lipoxygenase inhibitory (MDDR) \\
Stigmasterin (Stigmasterol) & Hypolipidemic (CMC) \\
\hline
\end{tabular}

\section{Conclusions}

Since only a small part of natural medicinal components have been documented in medicinal databases, the presently identified vegetable and legume functional components are only the tip of the iceberg. It is expected that with the progress of medicinal chemistry and pharmacology, more and more antidiabetic agents will be identified from foods. In fact, in a very recent study, it was reported that some triterpenoids derived from bitter melon are promising antidiabetic agents [19]. 
In nutrition studies, it is always a challenge to pinpoint the functions of food components to elucidate the epidemiological discoveries. The present study indicates that it is possible to explain (although partially) the health benefits of foods from the activities annotated in medicinal databases, which is of great significance to the study of food science and technology and even drug discovery.

\section{Acknowledgements}

This study was supported by the National Basic Research Program of China (grant 2003CB114400) and the National Natural Science Foundation of China (grant 30570383).

\section{References and Notes}

1. Tulp, M.; Bruhn, J. G.; Bohlin, L. Food for thought. Drug Discov. Today 2006, 11, 1115-1121.

2. Zhang, H.-Y. Can food-derived multipotent agents reduce the risk of Alzheimer's disease? Trends Food Sci. Technol. 2007, 18, 492-495.

3. Trichopoulou, A.; Costacou, T.; Bamia C.; Trichopoulos, D. Adherence to a Mediterranean diet and survival in a Greek population. New Engl. J. Med. 2003, 348, 2599-2608.

4. Scarmeas, N.; Stern, Y.; Tang, M. X.; Mayeux, R.; Luchsinger, J. A. Mediterranean diet and risk for Alzheimer's disease. Ann. Neurol. 2006, 59, 912-921.

5. Yang D.-P.; Kong D.-X.; Zhang, H.-Y. Multiple pharmacological effects of olive oil phenols. Food Chem. 2007, 104, 1269-1271.

6. Fujiki, H.; Suganuma, M.; Imai, K.; Nakachi, K. Green tea: Cancer preventive beverage and/or drug. Cancer Lett. 2002, 188, 9-13.

7. Chen, L.; Zhang, H.-Y. Cancer preventive mechanisms of the green tea polyphenol (-)epigallocatechin-3-gallate. Molecules 2007, 12, 946-957.

8. Kuriyama, S.; Hozawa, A.; Ohmori, K.; Shimazu, T.; Matsui, T.; Ebihara, S.; Awata, S.; Nagatomi, R.; Arai, H.; Tsuji, I. Green tea consumption and cognitive function: a cross-sectional study from the Tsurugaya Project. Am. J. Clin. Nutr. 2006, 83, 355-361.

9. Villegas, R.; Shu X.-O.; Gao Y.-T.; Yang G.; Elasy, T.; Li H.-L.; Zheng W. Vegetable but not fruit consumption reduces the risk of type 2 diabetes in Chinese women. J. Nutr. 2008, 138, 574580.

10. Villegas, R.; Gao Y. -T.; Yang, G.; Li, H.-L.; Elasy, T. A.; Zheng, W.; Shu, X.-O. Legume and soy food intake and the incidence of type 2 diabetes in the Shanghai Women's Health Study. Am. J. Clin. Nutr. 2008, 87, 162-167.

11. Traditional Chinese Medicine Database (TCMD), NeoTrident Technology Ltd.: Beijing, China, 2005; (http://www.natural-products.com.cn/)

12. Cheng, A. Y.; Fantus, I. G. Oral antihyperglycemic therapy for type 2 diabetes mellitus. Can. Med. Assoc. J. 2005, 172, 213-226.

13. Li, J.; Tian, H. M.; Tong, N. W. Progress in drug therapy for diabetic retinopathy. West China Med. J. 2007, 22, 440-442.

14. Luo, J.; Chuang, T.; Cheung, J.; Quan, J.; Tsai, J.; Sullivan, C.; Hector, R. F.; Reed, M. J.; Meszaros, K.; King, S. R.; Carlson, T. J.; Reaven, G. M. Masoprocol (nordihydroguaiaretic acid): 
a new antihyperglycemic agent isolated from the creosote bush (Larrea tridentata). Eur. J. Pharmacol. 1998, 346, 77-79.

15. Magee, M. F.; Taiwo, A. A.; Howard, B. V. Management of diabetes with coronary artery disease. Curr. Treat. Opt. Cardiovasc. Med. 2003, 5, 75-88.

16. Škrha, J. Diabetes and vascular disease: From pathogenesis to treatment: Are vascular effects of hypoglycemic and hypolipidemic drugs independent of their metabolic effects? Diabetes Metabol. Synd.: Clin. Res. Rev. 2007, 1, 61-69.

17. Comprehensive Medicinal Chemistry (CMC), MDL Information Systems Inc.: San Leandro, CA (USA), 2004; (http://www.mdl.com).

18. MDL Drug Data Report (MDDR), MDL Information Systems Inc.: San Leandro, CA (USA), 2004; (http://www.mdl.com).

19. Tan, M.-J.; Ye, J.-M.; Turner N.; Hohnen-Behrens, C.; Ke, C.-Q.; Tang, C.-P.; Chen, T.; Weiss, H.-C.; Gesing, E.-R.; Rowland A.; James, D. E.; Ye, Y. Antidiabetic activities of triterpenoids isolated from bitter melon associated with activation of the AMPK pathway. Chem. Biol. 2008, 15, 263-273.

(C) 2008 by the authors; licensee Molecular Diversity Preservation International, Basel, Switzerland. This article is an open-access article distributed under the terms and conditions of the Creative Commons Attribution license (http://creativecommons.org/licenses/by/3.0/). 